Volume 8. No. 9, September 2020

International Journal of Emerging Trends in Engineering Research

Available Online at http://www.warse.org/IJETER/static/pdf/file/ijeter91892020.pdf

https://doi.org/10.30534/ijeter/2020/91892020

\title{
Study of the Synthesis of the Stabilizer SG-1 by Phosphorylation of HIPAN
}

\author{
Sunatilla Baxodirjanovich Gaibnazarov ${ }^{1}$, Zumrat Talatovna Gaibnazarova ${ }^{2}$ \\ ${ }^{1} \mathrm{PhD}$, Associate Professor, Dean of the faculty «Mining and metallurgy» Tashkent State Technical University named after \\ Islam Karimov. str. Universitetskaya 2, Tashkent 100095, Uzbekistan, \\ sunnatilla29@rambler.ru \\ ${ }^{2} \mathrm{PhD}$, Associate Professor, Doctoral student of the department «Corporate governance» Tashkent State Technical University \\ named after Islam Karimov. str. Universitetskaya 2, Tashkent 100095, Uzbekistan, \\ zumrat59@rambler.ru
}

\begin{abstract}
Some issues of the creation of stabilizing reagents based on HIPAN and secondary raw materials are considered. In laboratory conditions, a polymer reagent based on HIPAN was synthesized, combining the specific properties of CMC and HIPAN. Kinetic laws and the mechanism of grafted copolymerization are established. The integral composition of the copolymers is determined. The main physicochemical, rheological and applied properties of the developed stabilizer-reagents are revealed. The dependences of the applied properties of the developed drilling fluids on the geological and structural properties of oil and gas fields are shown.
\end{abstract}

Key words: drilling, water loss, filtration, bentonite, drilling mud, waste.

\section{INTRODUCTION}

As domestic and foreign experience shows, the successful drilling of deep wells largely depends on the quality of the drilling fluids used, as a factor ensuring trouble-free well drilling. Most accidents and complications are caused by the use of a drilling fluid that is not appropriate for the drilling conditions. The need to increase the volume of drilling operations in order to explore deeply productive sediments requires the use of flushing fluids that can provide long-term stability of the wellbore, withstand high temperatures (more than $100-120^{\circ} \mathrm{C}$ ), at the same time have good lubricating properties and guarantee highquality opening of reservoirs [1].

In the drilling of oil and gas wells, to regulate the drilling processes and rheological properties of concentrated suspensions, stabilizers are used - organic chemical additives that can purposefully change the mobility of raw mixtures and the properties of drilling fluids. The search for new effective additives to modify the interface and change the rheological properties of dispersions is an urgent task [2-3].

\section{OBJECTS AND METHODS RESEARCH}

The special properties of stabilizing surfactants include the ability to stabilize dispersions and emulsions by adsorption of hydrophilic macromolecules at the phase boundary, which prevents particle aggregation; effect on the rheology of solutions and dispersions; ability to form physical gels; the ability to cause particle aggregation in stable dispersed systems to facilitate the separation of liquid and solid phases; modification of surface properties upon adsorption of particles on them to ensure wettability; solubilization of hydrophobic substances [4].

The aim of the studies considered in this article is to develop a technology for producing organic stabilizers based on local raw materials and to improve the technology for producing drilling fluids with their help. Oligomeric additives for drilling fluids based on the phosphorylation products of hydrolyzed polyacrylonitrile (HIPAN) were synthesized. Phosphorylation of hydrolyzed polyacrylonitrile produces phosphorus derivatives of HIPAN.

HYPANe phosphorylation was carried out in the presence of Friedel-Crafts catalysts, according to the procedure described in [5].

\section{EXPERIMENTS AND RESULTS}

In a four-necked flask equipped with a stirrer, thermometer, capillary for purging with argon and a separatory funnel, 5 moles of ATPF, solvent-dioxane (200 $\mathrm{g})$, copper shavings were placed. At a temperature of about $75{ }^{\circ} \mathrm{C}$, intensively mixing, slowly added dropwise phosphorylating agent $-\mathrm{PCl}_{3}$ and $\mathrm{AlCl}_{3}$ catalyst (5:1 ratio). Then the solution was stirred for 4 hours at a temperature of $60{ }^{\circ} \mathrm{C}$. After a thick mass formed, the reaction product was filtered with a glass filter and washed with a large amount of absolute ether, dried in vacuum at room temperature. The yield of phosphorylated product is 90 $95 \%$.

The composition and structure of the phosphorylated product are identified by the results of elemental analysis, IR, PMR spectroscopy and others [6].

In the IR spectrum of HIPAN, absorption bands of stretching vibrations of the $\mathrm{CH}$ group in the region of 2957 $\mathrm{cm}^{-1}$ appear which have a separately weakly pronounced maximum. The stretching vibrations of carbonyl groups are manifested by a maximum in the region of $1667 \mathrm{~cm}^{-1}$. The stretching vibrations of $\mathrm{NH}_{2}$ and $\mathrm{OH}$ are manifested by an intense, wide band in the absorption region of 3250 $3500 \mathrm{~cm}^{-1}$, and the deformation vibrations of $\mathrm{NH}$ are manifested in the region of $1563 \mathrm{~cm}^{-1}, 1451 \mathrm{~cm}^{-1}, 1408$ $\mathrm{cm}^{-1}$ belong to the $\mathrm{CH}_{2}-\mathrm{CO}$ groups, $1326 \mathrm{~cm}^{-1}$ include $\mathrm{CN}$ - bonds, $680 \mathrm{~cm}^{-1}$ deformation vibrations $-\mathrm{C}-\mathrm{H}$ bonds, $2120 \mathrm{~cm}^{-1}$ asymmetric valence vibrations of $-\mathrm{C} \equiv \mathrm{N}$ groups in Figure 1, spectrum 1. 
The IR spectrum of phosphorylated HIPAN shows a broad intense band at $3400 \mathrm{~cm}^{-1}$ for the $\mathrm{OH}$ group, and the absorption band at $2162 \mathrm{~cm}^{-1}$, -CN groups, $1659 \mathrm{~cm}^{-1}$, the absorption band of bending vibrations of $-\mathrm{NH}_{2}$ groups, 1407, $1454 \mathrm{~cm}^{-1}$, deformation vibrations of $\mathrm{CH}_{2}$ groups, 1353-1325, $712 \mathrm{~cm}^{-1}$, a low-intensity absorption band belongs to stretching vibrations $-\mathrm{CH}$ bonds. The stretching vibration of the $-\mathrm{C} \equiv \mathrm{N}$ - bond of $2120 \mathrm{~cm}^{-1}$ disappears due to the formation of a new chemical bond $-\mathrm{C}=\mathrm{P}+\delta \ldots \mathrm{O}-\delta$ in the region of $1350 \mathrm{~cm}^{-1}$. At the same time, new intense absorption bands are also formed in the region of 1050 $1100 \mathrm{~cm}^{-1}$, which are related to asymmetric vibrations of the ether bond (-C-O-C-) due to the opening of the carboxy group $\left(1250,930 \mathrm{~cm}^{-1}\right)$ of HIPAN during phosphorylation. It was found that in the IR spectrum of phosphorylated HIPAN in Figure 1, spectrum 2, the band corresponding to stretching vibrations of the -C-O-P bond is shifted to the low-frequency region to $1350 \mathrm{~cm}^{-1}$, compared with that in the $\mathrm{PCl}_{3}$ spectrum.

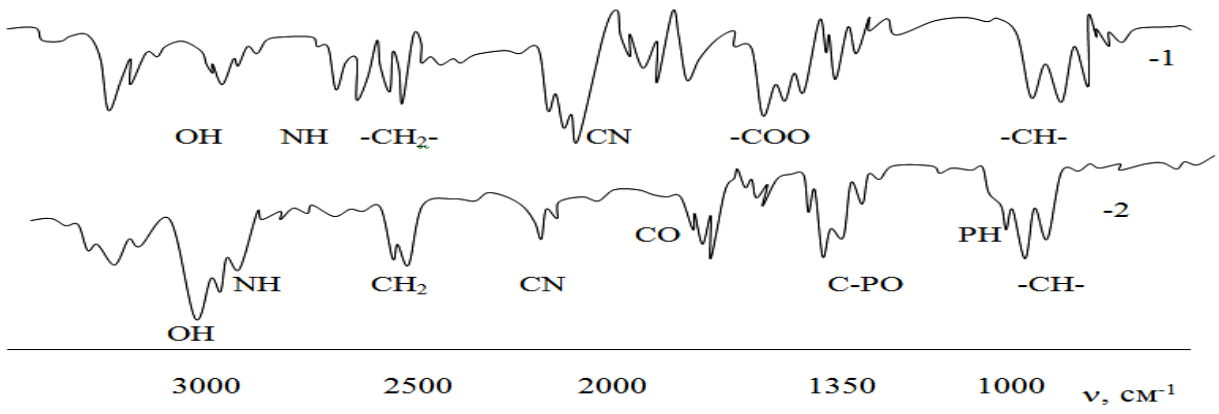

Figure 1: IR spectra:

1 - HIPAN, 2 - phosphorylated HIPAN

The presence of carbon-heteroatom bonds in phosphorylated HIPAN is proved experimentally. For example, during polymer-analogous transformations of phosphorylated HIPAN, the molecular weight of the polymer when treated with aqueous solutions of alkalis decreases only at the first stage of processing, and then remains constant. Apparently, phosphorylated HIPAN contains a certain amount of ketene-phosphine bonds $\mathrm{CH}_{2}=-\mathrm{P}$-, which are easily hydrolyzed by alkali. After the destruction of these bonds in the polymer, only phosphorus-carbon bonds resistant to hydrolysis remain, due to which the molecular weight of the polymer does not change further. The availability of functional groups in the case of bulky side moieties is greatly influenced by the process of polymer-analogous transformations due to steric difficulties, this availability is much less than in ordinary low molecular weight substrates. Neighboring groups, which can accelerate or slow down the process, for example, the acetate group located between two hydroxyl groups, hydrolyze two orders of magnitude faster than the one between two acetate, have a great influence on the reaction of polymer-analogous transformations. This is because the local alkali concentration increases (due to the adsorption of $\mathrm{OH}$-ions on hydroxyl groups) in the region of the hydrolyzable group. As can be seen from the IR spectra of the products of the hypane phosphorylation, there are absorption bands in the region of $1070-1150 \mathrm{~cm}^{-1}$. These absorption bands characterize the -C-O-P- chemical bonds [7-9]. The IR spectrum also has absorption bands characterizing the $\mathrm{C}-\mathrm{OH}$ bonds of the non-reacting polybasic alcohol in the region of $3200-3600 \mathrm{~cm}^{-1}$.

The phosphorylated HIPAN synthesized in this way is a yellow viscous liquid, a dry residue of at least $60 \%$, a density of $1.07-1.09 \mathrm{~g} / \mathrm{dm}$. The number of carboxyl groups $45-49 \%$, molecular weight of the order of $5 \cdot 10^{4}$.

Based on the results of studying the IR spectra, it can be seen that the reactions of interaction between HIPAN and $\mathrm{PCl}_{3}$ proceed according to the following mechanism:

$$
\begin{aligned}
& \left(-\mathrm{CH}_{2}-\underset{1}{\mathrm{CONH}}-\mathrm{CH}_{2}-\underset{\mathrm{COONa}}{\mathrm{CH}}-\mathrm{CH}_{\mathrm{CN}}^{\mathrm{CH}}-\right)_{\mathrm{n}}+\mathrm{PCI}_{3} \frac{+\mathrm{Cu}, \mathrm{AlCl}_{3}}{-\mathrm{NaCl}} \\
& \longrightarrow \quad\left(-\mathrm{CH}_{2}-\underset{\mathrm{CONH}}{\mathrm{CH}}-\mathrm{CH}_{2}-\underset{\mathrm{COOPO}(\mathrm{OH})_{2}}{\mathrm{CH}}-\underset{\mathrm{CN}}{\mathrm{CH}}-\right)_{n}
\end{aligned}
$$

This can be explained by the absence of characteristic signs of optical properties in the case of phosphorylated HIPAN inherent in $\mathrm{PCl}_{3}$, such as exaltation of molecular refraction (that is, there are no perturbations of the dispersion curve in the visible region due to intrinsic absorption of molecules), known characteristic changes in IR, PMR and UV spectra in Figure 2, 3. As for the chemical properties, it seems that the substituent (-P-O-) does not interfere with the transfer of charges by the mechanism of the electric effect, but weakens it. These features of the behavior of $\mathrm{PCl}_{3}$ in the system are the result, firstly, of non-coplanar systems and, secondly, the participation of $3 \mathrm{~d}$ phosphorus orbits in conjugation. 


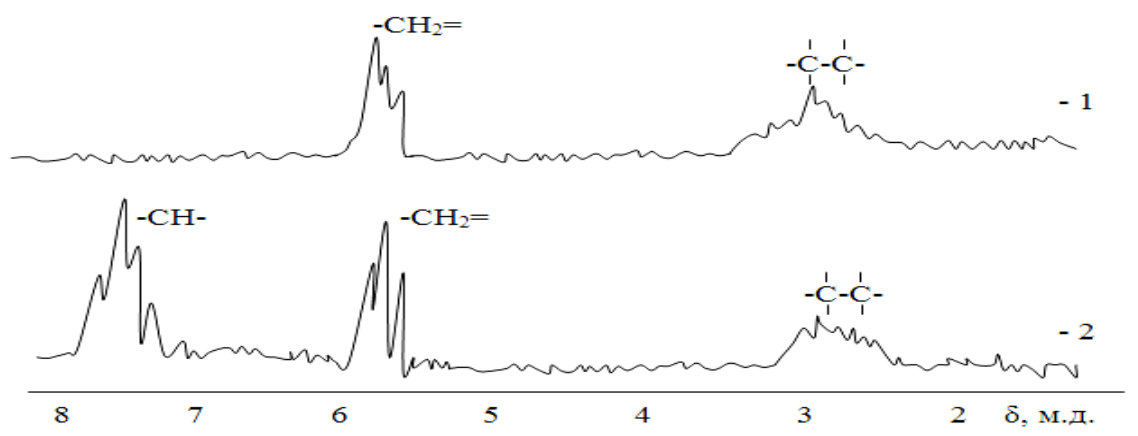

Figure 2: PMR spectra:

1 - HIPAN, 2 - phosphorylated HIPAN

Thus, substituents influence the constants of the phosphorylation process. These influences obey a single pattern and are identical in nature. The only difference is that the effect transmitted through the phosphorus atom in the case of $\mathrm{PC}_{3}$ is weakened by about 2 times.

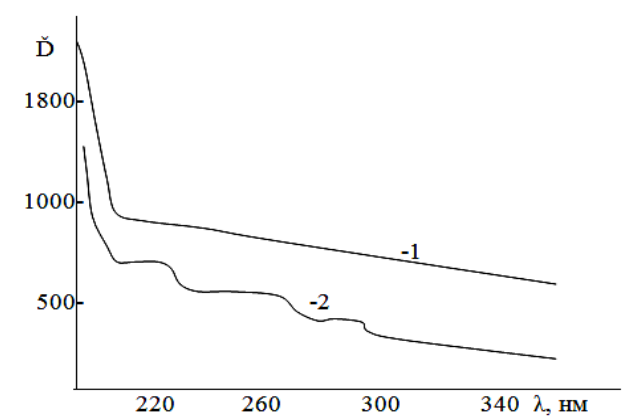

Figure 3: UV absorption spectra: 1 - HIPAN, 2 - phosphorylated HIPAN. $\left(\mathrm{C}=1 \cdot 10^{-3} \mathrm{~mol} / \mathrm{L}\right.$, ethanol $)$

When studying the PMR spectra of the obtained phosphorylated polyol, in contrast to the PMR spectrum of HIPAN, an broadened proton signal is observed in the region of 3.20-2.40 ppm, indicating the conservation of the -C-C-polymer bond in the polyol. Intense signals appear in the region of 7.60-8.00 ppm, indicating the formation of the -C-O-P- group, due to the interaction of HIPAN with $\mathrm{PCl}_{3}$. [10-12]

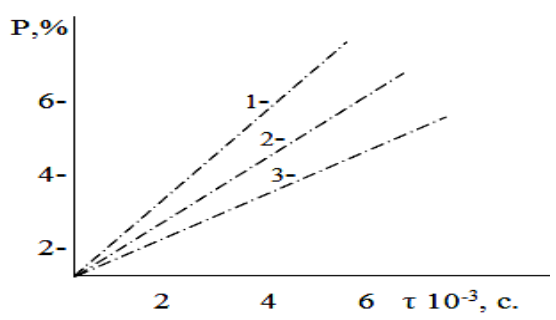

Figure 4: The influence of the nature of the solvent on the content of $\mathrm{P}$ during phosphorylation of HIPAN:

1 - dioxane; 2 - DMF; 3 - DMSO, $[\mathrm{M}]=0.5 \mathrm{~mol} / 1, \mathrm{~T}=60^{\circ} \mathrm{C}$

The reaction orders found depend relatively little on the nature of the solvent in Figure 4. This, however, does not mean that the solvents used are inert to reacting objects.
As the dielectric constant increases, the solvating ability of the solvent increases, and according to the theory of the cell effect, complexes between growing radicals and reagent and solvent molecules form in polar media. Therefore, during the phosphorylation of HIPAN in such media, solvation of polymer radicals by solvent molecules is possible, which reduces the reactivity of radicals, which, by solvating the radicals, increase the chain growth constant. Perhaps the latter circumstance is one of the reasons for the increase in the speed of the process in Figure 5 and the molecular weight of the resulting polyol upon phosphorylation in the medium of the above solvents in the Table 1.

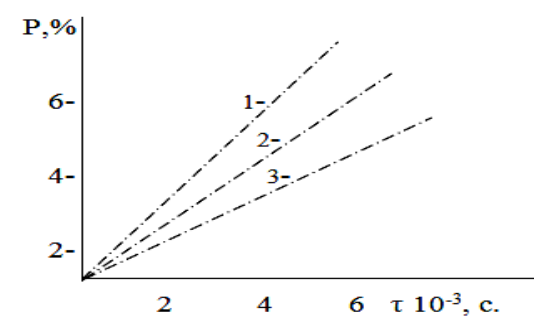

Figure 5: Dependence of the content of $\mathrm{P}$ on the duration of the HIPAN phosphorylation reaction:

1 - 1 hour, 2 - 3 hours, 3 - 5 hours;

In dioxane, $[\mathrm{M}]=0.5 \mathrm{~mol} / \mathrm{l}, \mathrm{T}=60^{\circ} \mathrm{C}$

Table 1: Influence of the nature of the solvent on the kinetic parameters of HYPAN phosphorylation

\begin{tabular}{|l|c|c|c|c|c|}
\hline \multirow{2}{*}{ Solvent } & \multirow{2}{*}{} & \multirow{2}{*}{$\mathbf{V} \mathbf{~ m o l} / \mathbf{m}^{\mathbf{3}}$} & \multirow{2}{*}{$\mathbf{K p} / \mathbf{K o} \mathbf{0}^{\mathbf{0 , 5}}$} & \multicolumn{2}{|c|}{$\begin{array}{c}\text { Reaction } \\
\text { order }\end{array}$} \\
\cline { 5 - 6 } & $\mathbf{3}$ & & & {$[\mathbf{M}]$} & {$\left[\mathbf{P C 1}_{3}\right]$} \\
\hline Dioxane & & 5,23 & 34,8 & 1,40 & 0,52 \\
\hline DMF & 36,7 & 4,68 & 30,5 & 1,42 & 0,53 \\
\hline DMSO & 48,9 & 3,45 & 24,4 & 1,53 & 0,57 \\
\hline
\end{tabular}

The reaction order according to $\mathrm{HIPAN}$ and $\mathrm{PC1}_{3}$ was determined in a series of experiments on the phosphorylation of HIPAN. The initial phosphorylation rate is described by the following empirical equations:

$$
\begin{aligned}
& \text { in water } \mathrm{W}=\mathrm{K}[\mathrm{M}]^{1,40}\left[\mathrm{PC}_{3}\right]^{0,52} \\
& \text { in DMF } \mathrm{W}=\mathrm{K}[\mathrm{M}]^{1,42}\left[\mathrm{PC}_{3}\right]^{0,53} \\
& \text { in DMSO } \mathrm{W}=\mathrm{K}[\mathrm{M}]^{1,53}\left[\mathrm{PC}_{3}\right]^{0,57}
\end{aligned}
$$


This is consistent with the basic patterns of the phosphorylation reaction [13]. The somewhat overestimated order of HIPAN is apparently due to a number of factors associated with the formation of specific HIPAN and radical complexes with other components of the system (catalyst and solvent molecules) due to unshared electron pairs of phosphorus, oxygen, or the possible participation of the polymer in chain transfer events. In addition, it is well known that the stages of initiation (more precisely, the exit of the initiating radical from the cell) and chain termination during phosphorylation are diffusion-controlled processes. Therefore, if the viscosity of the polymer-solvent mixture is significantly different from the viscosity of the polymer, this factor can affect the rate of phosphorylation and oxidation [14].

The order of the reaction according to the concentration of the catalyst indicates a bimolecular mechanism of chain termination due to the recombination of radicals.

The kinetic parameters of the phosphorylation process were determined using the formula:

$$
\mathrm{W}_{\mathrm{o}} /\left[\mathrm{M}_{\mathrm{o}}\right]=\left(\mathrm{f} \cdot \mathrm{K}_{\mathrm{rasp}}\right)^{0,5}\left(\mathrm{~K}_{\mathrm{p}} / \mathrm{K}_{\mathrm{o}}^{0,5}\right) \cdot\left[\mathrm{PCl}_{3}\right]^{0,5}
$$

here: $\mathrm{W}_{\mathrm{o}}$ - initial phosphorylation rate, $\mathrm{mol} / \mathrm{l} \mathrm{s} ; \mathrm{K}_{\mathrm{p}}, \mathrm{K}_{\mathrm{o}}$, and $\mathrm{K}_{\text {rasp }}$ are the constants of the growth rate, chain termination, and decomposition of the catalyst; $\mathrm{f}$ is the phosphorylation efficiency.

From the values of $\mathrm{W}_{\mathrm{o}}$ using the values $\mathrm{K}_{\text {rasp }}=12 \cdot 10^{-6} \mathrm{~s}^{-1}$ and $\mathrm{f}=0.57$, the ratio $\mathrm{K}_{\mathrm{p}} / \mathrm{K}_{\mathrm{o}}^{0,5}$ was calculated for temperatures of $60{ }^{\circ} \mathrm{C}, 70{ }^{\circ} \mathrm{C}$ and $80{ }^{\circ} \mathrm{C}$.

It was found that the dependence of the induction period of phosphorylation in the presence of catalysts is linear, and the stationary process rate after the induction period is almost equal to the rate of phosphorylation. The data obtained indicate a sufficiently high efficiency of the phosphorylating agent used. As can be seen, the values of $\mathrm{K}_{\mathrm{p}} / \mathrm{K}_{\mathrm{o}}^{0,5}$ determined experimentally from the dependence of the phosphorylation time on the concentration of $\mathrm{PCl}_{3}$ in the range of $60-80{ }^{\circ} \mathrm{C}$ are almost close to the calculated ones, which confirms the reliability of the established kinetic ordinal values of the HIPAN phosphorylation process in Figure 6.

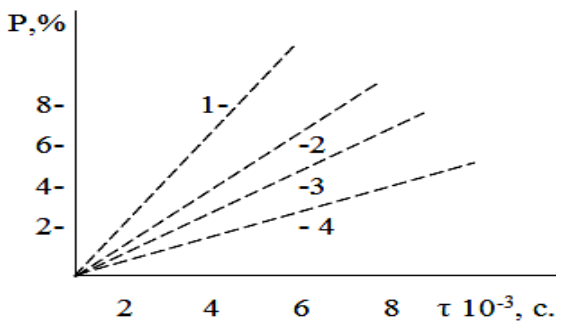

Figure 6: The dependence of the content of $\mathrm{P}$ on the duration of the reaction at different temperatures:

$$
1-70{ }^{\circ} \mathrm{C}, 2-60{ }^{\circ} \mathrm{C} ; 3-50{ }^{\circ} \mathrm{C} ; 4-40{ }^{\circ} \mathrm{C} \text {. }
$$$$
\text { In dioxane, }[\mathrm{M}]=0.5 \mathrm{~mol} / \mathrm{L}
$$

In the process of obtaining the stabilizer SG-1 based on HIPAN with phosphorus trichloride in the presence of aluminum trichloride and copper chips, temperature also plays a special role. Below in Figure 7 shows the dependence of the output of the stabilizer SG-1 on the reaction temperature. Four ratios of initial products were selected.

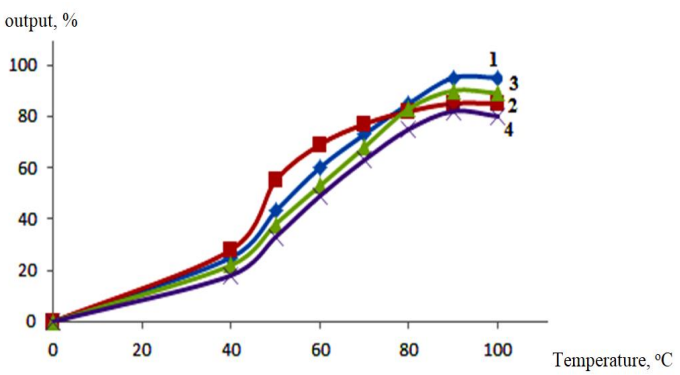

Figure 7: The dependence of the output of the stabilizer SG-1 on temperature:

The molar ratio of hydrolyzed polyacrylonitrile, $\mathrm{PCl}_{3}$, copper and $\mathrm{AlCl}_{3}$;

1 - 1:1:1; 2 - 1:1:2; 3 - 1:2:1; 4 - 2:1:1

As can be seen from Figure 7 , the optimal ratio of components upon receipt of the stabilizer SG-1 is $1: 1: 1$, and the optimum temperature is $80{ }^{\circ} \mathrm{C}$. Under these conditions, the stabilizer yield is $95 \%$. The highest dry residue is obtained when the ratio of initial products is $2: 1: 1$ and $1: 2: 1$, but the plasticizing effect (or quality) of the obtained stabilizer is low. Based on this, to obtain the stabilizer SG-1, the optimal temperature of $80{ }^{\circ} \mathrm{C}$ was chosen.

In the production of chemical products, the duration of the reaction also plays an important role. To select the optimal reaction yield temperature, four ratios of initial products were also selected. Below in Figure 8, the dependence of the output of the stabilizer SG-1 on the reaction time at a temperature of $80^{\circ} \mathrm{C}$ is shown.

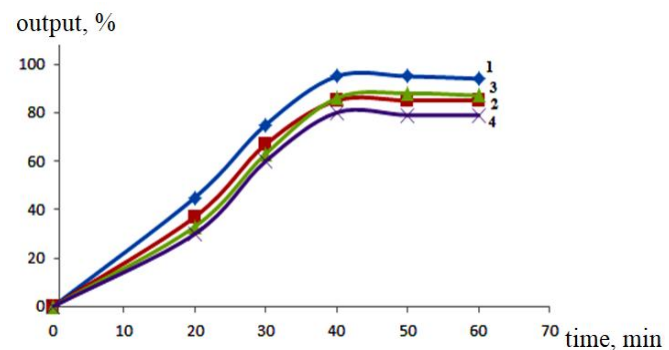

Figure 8: The dependence of the output of the stabilizer SG-1 on time:

The molar ratio of hydrolyzed polyacrylonitrile, copper, $\mathrm{PCl}_{3}$ and $\mathrm{AlCl}_{3}$ $1-1: 1: 1 ; 2-1: 1: 2 ; 3-1: 2: 1 ; 4-2: 1: 1$

As can be seen from figure $8,95 \%$ yield of the stabilizer SG-1 is obtained by carrying out the reaction under optimal conditions for 40 minutes. Further reaction under these conditions leads to a decrease in yield. This is due to the strengthening of parallel reactions (such as crosslinking, decomposition, intermolecular interaction, and others), which lead to a decrease in the plasticizing effect of oligomeric stabilizing additives.

\section{CONCLUSION}

Thus, the optimal conditions for obtaining the stabilizer SG-1 is to conduct the reaction at a temperature of $80^{\circ} \mathrm{C}$ for 40 minutes, with a ratio of components $1: 1: 1$. The 
product obtained under these conditions has a very good plasticizing effect. Further study of the influence of the stabilizer SG-1 on the properties of drilling fluids is carried out by the product obtained under the above conditions.

\section{REFERENCES}

1. S.B.Gaibnazarov. Study physic-chemical characteristic polymer applicable in bore solution, Austrian Journal of Technical and Natural Sciences, Austria, Vienna, №9-10, 2015, P.104-107.

2. S.B.Gaibnazarov. Study of the effect of polymer reagents on the thixotropy of drilling fluids, Scientific and Technical Journal Chemical Industry, St.Petersburg, 2016, №5, P.258-261.

3. S.B.Gaibnazarov, B.A.Aliev. Effective reagents for drilling fluids based on secondary resources, Materials of the I International Scientific and Practical Conference Bulatov Readings, Krasnodar, March 31, 2017, P.116-117.

4. S.B.Gaibnazarov. Stabilization of drilling fluids with treated bentonite of the Navbahor deposit, Scientific and Technical Journal Vestnik TSTU, Tashkent, 2019, №1, P.174-179.

5. S.B.Gaibnazarov, B.A.Aliev. Development and research of new drilling fluid stabilizers, Doklady of the Academy of Sciences of the Republic of Uzbekistan, Tashkent, 2017, №2, P.61-65.

6. A.A.Raupov, S.B.Gaibnazarov, A.M.Aminov, D.K.Nazarbekova. Drilling mud for prevention of dispersion and swelling of clay rocks of various genesis, Journal of Critical Reviews. Vol. 7, Issue 9. P. 511-513. http://dx.doi.org/10.31838/jcr.07.09.101

7. Gaibnazarova Zumrat Talatovna, Gaibnazarov Sunatilla Baxodirjanovich. Development of education system in the context of world experience and national specificity as an investment in human capital, Journal of Critical Reviews. Vol 7, Issue 12, 2020.P.302-308. http://dx.doi.org/10.31838/jcr.07.12.57

8. S.B.Gaibnazarov. Physicochemical and macromolecular characteristics of new stabilizers of drilling fluids, Chemistry and chemical technology. 2017. №1 (55). P. 48-52.

9. S.B.Gaibnazarov. Study of influence of polymer reagents on thixotropy of drilling fluids, Chemical industry. 2016. Vol. 93 No. 5. P. 258-261.

10. S.B.Gaibnazarov. Development of new polymer reagents-stabilizers of drilling fluids, Chemical industry. 2016. Vol. 93 No. 5. P. 262-265.

11. S.B.Gaibnazarov. Studying properties of polymer stabilizers of drilling fluids, Chemical industry. 2016 T. 93. No. 4. P. 209-212.

12.S.B.Gaibnazarov. The prospects of the using secondary resource in development efficient bore solution, Austrian Journal of Technical and Natural Sciences. Austria, Vienna, 2016. № 3-4. P. 114-117.

13. A.A.Raupov, S.B.Gaibnazarov. Without Clay Drilling Fluids for Well Bore Wiring in Complicated Conditions, International Journal of Engineering and Advanced Technology (IJEAT) ISSN: 2249 - 8958, Volume-9 Issue-2, December, 2019. http://dx.doi.org/10.35940/ijeat.B3676.129219
14.Z.I.Zaripov, A.U.Aetov, F.M.Gumerov, V.G.Nikitin, S.V.Mazanov, A.R.Gabitova, A.I.Kurdyukov. The Regularities of Change of Organic Compounds Oxidation Activation Energy in Aqueous Medium Under Supercritical Fluid Conditions, International Journal of Emerging Trends in Engineering Research, Volume 8, No. 1 January 2020 P.182-194. https://doi.org/10.30534/ijeter/2020/25812020

15. M.S.Saitkamolov, Z.T. Gaibnazarova, Cowie J. Modern model for assessing the efficiency of investments attracted in railway transport, Technical science and innovation, Volume 2020, Issue 1. https://uzjournals.edu.uz/btstu/vol2020/iss1/5

16.Z.T.Gaibnazarova. Human capital as an intense factor of the development of industry and driver of innovative waves, International Finance and Accounting, Volume 2020, Issue 1. https://uzjournals.edu.uz/interfinance/vol2020/iss1/24

17. S.B.Gaibnazarov. Prospects for the development of production of reagents for drilling solutions based on secondary resources, Technical science and innovation, Volume 2020, Issue 2, https://uzjournals.edu.uz/btstu/vol2020/iss2/10 